\title{
Histamine bronchial challenge: effect on regional ventilation and aerosol deposition
}

\author{
H CLAGUE, D AHMAD, MJ CHAMBERLAIN, WKC MORGAN, S VINITSKI
}

From the Chest Disease Service and Division of Nuclear Medicine, University Hospital, London, Ontario, Canada

ABSTRACT We studied regional changes in ventilation and aerosol deposition after histamine challenge in six patients with asthma and two with rhinitis and a history of wheezing. All were known to have bronchial hyperreactivity and all showed an increased response to histamine. Ventilation and aerosol deposition studies, using xenon-133 and an aerosol of sulphur colloid tagged with technetium $99 \mathrm{~m}$, were performed while they were sitting. Before administration of histamine radioaerosol scintiscans were abnormal in five of six patients; after histamine challenge all were abnormal and central deposition was significantly greater in all of them. The decrease in aerosol penetration correlated with the percentage decrease in $\mathrm{FEV}_{1}$, indicating that the efficiency of aerodynamic filtration depends on the degree of airway narrowing. In six of the eight subjects the distribution of ventilation changed from predominantly basal to predominantly apical after histamine, which suggests the airways response was greater, at least initially, in the better ventilated regions. This indicates a close relationship between regional ventilation and the site of histamine deposition and has implications for the delivery of aerosolised agents in general.

Inhalation bronchial provocation tests are frequently used in the diagnosis of asthma ${ }^{1}$ and the standardised histamine challenge test is said to provide a useful measure of bronchial hyperreactivity. ${ }^{2}$ Bronchial response is usually documented by change in ventilatory capacity or airways resistance, although a limitation of such tests is that they record an overall reduction in air flow or resistance and give no information about regional function. As the agents used for challenge tests are generally delivered to the bronchial tree as an aerosol, regional variations in airway calibre and ventilation are likely to be important in determining aerosol distribution and bronchial response. We therefore examined whether a histamine aerosol challenge had any effect on regional ventilation and aerosol deposition and whether this could be anticipated from a study of lung function before the challenge.

Methods

SUBJECTS

Eight adults (two female) aged 27-57 years were

Address for reprint requests: Dr WKC Morgan, Chest Disease Service, University Hospital, Box 5339 Postal Station A, London, Ontario, Canada N6A 5A5.

Accepted 16 May 1983 selected because they were known to have increased bronchial responsiveness to inhaled histamine. Six $\stackrel{\odot}{\varnothing}$ were asthmatic, with a history of episodic wheezing $\stackrel{\varrho}{\rightarrow}$ and dyspnoea and a documented improvement in FEV , of greater than $20 \%$ spontaneously or after the use of bronchodilators. Two of the six (Nos 4 采 and 6) were cigarette smokers with a lifetime consumption of 6 and 20 pack years; patient 6 was having maintenance steroid treatment (prednisone $5 \mathrm{mg}$ daily). The other two subjects (Nos 2 and 7) had allergic rhinitis and a history of mild wheezing. All 3 participants gave written informed consent and the study was approved by the health sciences committee on human experimentation of the University of Western Ontario.

HISTAMINE CHALLENGE TEST

An inhaled histamine challenge test was performed in each subject with a slight modification of the method of Cockcroft and his associates. ${ }^{2}$ A Wright's nebuliser (Roxon, Medi-Tech, Montreal) was used $\omega$ to generate aerosols of physiological saline contain ing twofold increasing concentrations of hist- - O amine acid phosphate in the range $0.03-0.8 \mathrm{mg} / \mathrm{ml}$. Subjects wore a nose clip and inhaled aerosol from a? loosely fitting facemask during tidal breathing. Each $\frac{T}{-}$ inhalation continued for two minutes and was repe- $\frac{O}{D}$ ated at five minute intervals until a $15 \%$ fall in FEV 
occurred. The concentration causing a $15 \%$ fall in FEV was regarded as the threshold concentration. The FEV 1 was measured at the start of the study and repeat measurements were made 30 and 90 seconds after each inhalation. The Wright's nebuliser delivered $0.15 \mathrm{ml} / \mathrm{min}$ at an oxygen flow rate of $10 \mathrm{l} / \mathrm{min}$ and produced particles with a mass median diameter of $1.2 \mu \mathrm{m}$ (geometric standard deviation (GSD) $2 \cdot 2$ $\mu \mathrm{m})$. The subjects' forced vital capacity (FVC) and FEV $_{1}$ were expressed as percentages of the predicted values of Morris et al. ${ }^{3}$

\section{VENTILATION AND AEROSOL DEPOSITION STUDIES}

Ventilation and aerosol deposition studies were performed in the sitting position with xenon-133 gas $\left({ }^{133} \mathrm{Xe}\right)$ and technetium-99 m sulphur colloid aerosol ( $\left.{ }^{99 \mathrm{~m}} \mathrm{TcSC}\right)$ respectively. Posterior images that included both lung fields were made by continuous recording from a gamma camera on line to a dedicated computer, which permitted subtraction of background radiation and residual radiation from previous studies. The lung fields were arbitrarily divided into zones in a standardised and reproducible fashion (fig 1 ) to assess regional activity. ${ }^{4}$

The radiation dose for the four studies for each subject was about 500 millirads $(5 \mathrm{mGy})$ to the lungs and 5500 millirads ( $55 \mathrm{mGy}$ ) to the mucosa of the major airways. The ventilation and aerosol deposition studies were done immediately before and after histamine challenge to minimise effects due to spontaneous change in ventilation and aerosol deposition due to asthma.

\section{REGIONAL VENTILATION}

Regional ventilation was determined by a standard radioxenon rebreathing technique consisting of five minutes' rebreathing from a 101 xenon spirometer followed by five minutes' washout with continuous recording, divided into five second intervals. From the computer images of xenon redistribution complex time activity curves consisting of multiple exponents were obtained for each zone. The curves were analysed by a non-linear least square fitting method. The predominant component of the initial part of the curve represents alveolar ventilation, while other components relate to xenon dissolving and equilibrating with that in other body tissues. ${ }^{56}$ Regional alveolar ventilation per unit lung volume was calculated from the slope of the initial portion of the zonal complex washin curve. ${ }^{7}$ The initial portion of this curve was defined as that occupying twice the time taken for the regional count rate to reach one half of its maximum.

Because some subjects may not achieve equilibrium at five minutes, the distribution of regional lung volume was derived by extrapolation of the initial portion of each zonal curve, as suggested by Prato. ${ }^{8}$ An extended washin period was not used because the effect of histamine might wear off in a minority of subjects. Thus for each given lung zone (i) alveolar ventilation per unit lung volume $\left(\lambda_{i}\right)$ can be expressed as:

$$
\lambda_{\mathrm{i}}=-\ln \left[\frac{\mathrm{C}_{\mathrm{i}}(t)}{1-\mathrm{C}_{\mathrm{i}} \text { (equil) }}\right] / t,
$$

where $\mathrm{C}_{1}(t)$ is the observed count rate at a given time $(t)$ during the initial washin phase and $C_{i}$ (equil) is the equilibration count rate in zone $i$ and is proportional to regional lung volume in this zone. ${ }^{410}$ Ventilatory differences from zone to zone were calculated by the following formula:

$$
\mathrm{IV}_{\mathrm{i}}=100 \times \frac{\lambda_{\mathrm{i}}}{\lambda_{\mathrm{T}}}
$$

where $I V_{i}$ is the index of regional ventilation, $\lambda_{i}$ is alveolar ventilation per unit lung volume for zone $i$,
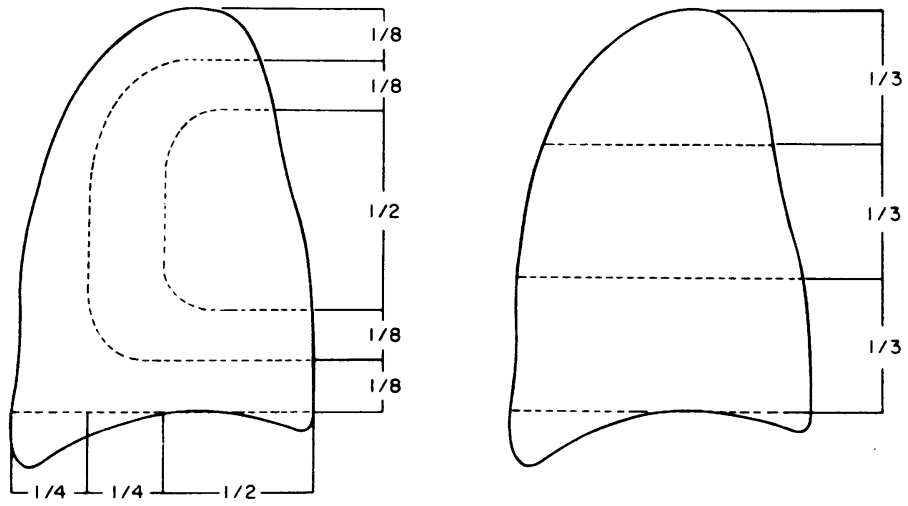

Fig 1 Method of dividing lung fields into central, intermediate, and peripheral zones and upper, mid, and lower zones. 
and $\lambda_{T}$ is alveolar ventilation per unit lung volume for the whole lung.

Alveolar ventilation was studied in the vertical plane using radioxenon to identify the apex to base gradient in ventilation and to determine whether regional ventilation was affected by disease, and if so how this influenced the distribution and response to inhaled histamine.

\section{REGIONAL AEROSOL DEPOSITION}

Regional aerosol deposition was determined by a modification of the technique of Hayes and Taplin.9 About $50-80 \mathrm{mCi}$ of ${ }^{99} \mathrm{~m}$ TcSC were placed in $4 \mathrm{ml}$ saline in a high flow nebuliser (Acorn VIX) and aerosolised with oxygen. The aerosol passed through two 51 bags, which acted as settling tanks for larger particles and facilitated normal tidal breathing. The aerosol was inhaled via a mouthpiece until sufficient aerosol deposition had occurred to permit subsequent imaging. About two minutes were necessary to obtain deposition of $300-500 \mu \mathrm{Ci}$ in the respiratory tract. The mass median diameter of particles at the mouth was $1.16 \mu \mathrm{m}$ (GSD 1.46). Aerosol deposition was expressed as a regional index as follows:

$$
\begin{aligned}
I_{i}= & 100 \times \\
& \frac{\text { deposition per unit volume in zone } i}{\text { deposition per unit volume in total lung }} \\
= & 100 \times \frac{A_{i}}{\mathrm{C}_{i} \text { (equil) }} \div \frac{\Sigma A_{i}}{\Sigma C_{i}(\text { equil) }},
\end{aligned}
$$

where $A_{i}$ and $\Sigma A_{i}$ are the counts due to labelled aerosol activity in zone $i$ and the whole lung respectively after a period of aerosol inhalation, $C_{i}$ (equil) and $\Sigma C_{i}$ (equil) are the equilibrium xenon counts in zone $i$, and the whole lung respectively. Xenon counts are used to normalise the aerosol counts for differences in volume between zones.

The penetration of inhaled particles to the lung periphery was expressed as an index of penetration (AeP):

$$
\mathrm{AeP}=\frac{\mathrm{IDc}}{\mathrm{IDp}},
$$

where IDc and IDp refer to indices of aerosol deposition in central and peripheral zones respectively.

Initial deposition of aerosol particles in subjects with significant airways obstruction has alveolar and tracheobronchial components. The most practical method of separating alveolar from deadspace deposition is to repeat the imaging 24 hours later when the deadspace fraction will have been removed by the mucociliary escalator and coughing. Residual activity is then assumed to reflect alveolar deposition. This was not possible in the present study since the studies that preceded and followed aerosol inhalation had to be carried out within a few minutes of each other, and this would have caused a superimposition of images from one study on those of the next. To overcome this and gain some estimate of the effect of histamine on airways, aerosol penetration was examined in concentric or radial planes (fig 1). Since large airways predominate in the central zone, any reduction in peripheral penetration due to histamine will be reflected by higher central counts.

\section{PROTOCOL}

The sequence of procedures for each subject was as follows:

(1) assessment of ventilatory capacity; (2) xenon study of ventilation; (3) radioaerosol study; (4) histamine challenge; (5) repeat aerosol study; (6) repeat xenon study; (7) repeat assessment of ventilatory capacity. The time from the end of histamine challenge to completion of the repeat xenon study was about 15 minutes; but as only the first two minutes of the xenon washin curve were used all the measurements used in the calculations were made after six to seven minutes.

\section{Results}

Table 1 summarises the results of initial spirometry and response to histamine. Threshold concentrations of histamine tended to be lower and produce a greater effect in subjects with asthma, particularly those with airflow obstruction. The average increase in FEV from the end of the histamine challenge to the final assessment was $18 \%$. In no instance had the $\mathrm{FEV}_{1}$ returned to normal; in most subjects improvement was $200-350 \mathrm{ml}$.

\section{VENTILATION STUDIES}

Before histamine challenge

Different degrees of ventilation non-uniformity

Table 1 Spirometric values for the eight subjects with the percentage fall in FEV, (values in parentheses are the percentages of predicted values ${ }^{3}$ )

\begin{tabular}{lllll}
\hline $\begin{array}{l}\text { Subject } \\
\text { No }\end{array}$ & $\begin{array}{l}F V C \\
(l)\end{array}$ & $\begin{array}{l}\text { FEV } \\
(l)\end{array}$ & $\begin{array}{l}\text { \% fall } \\
\text { in FEV, }\end{array}$ & $\begin{array}{l}\text { Threshold } \\
\text { histamine } \\
\text { concentration } \\
(\text { mg/ml) }\end{array}$ \\
\hline 1 & & & & \\
2 & $6.34(100)$ & $4.01(89)$ & 32 & 1.0 \\
3 & $4.30(85)$ & $3.30(83)$ & 21 & 4.0 \\
4 & $3.60(60)$ & $1.80(40)$ & 39 & 0.125 \\
5 & $4.40(94)$ & $3.10(83)$ & 29 & 0.5 \\
6 & $3.40(105)$ & $2.20(88)$ & 20 & 0.25 \\
7 & $3.35(86)$ & $2.35(78)$ & 26 & 4.0 \\
8 & $4.75(97)$ & $3.85(95)$ & 16 & 8.0 \\
\hline
\end{tabular}


IV
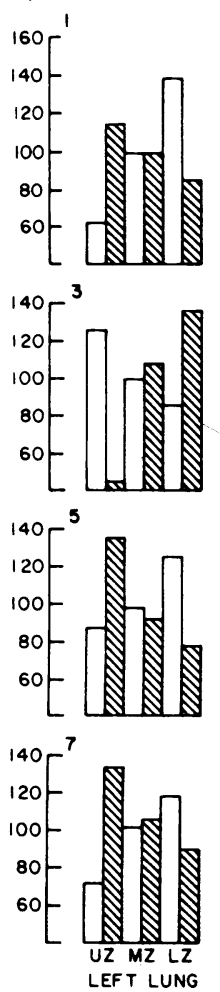
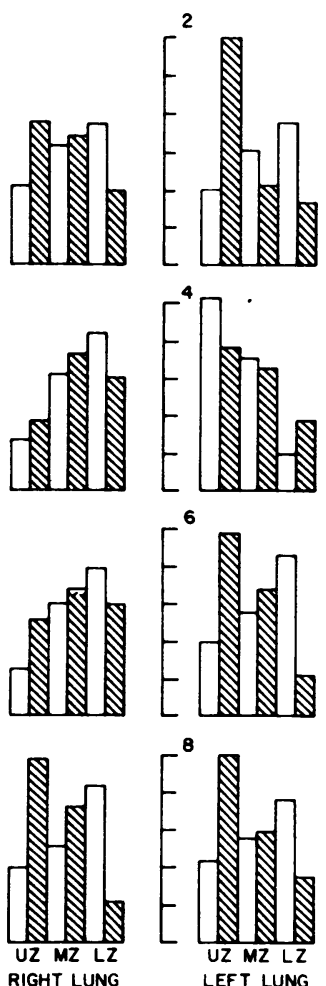
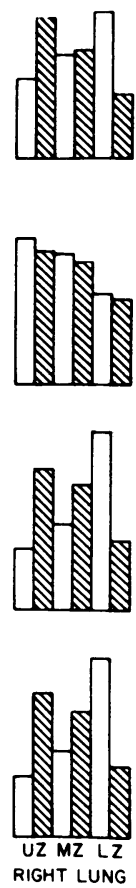

Fig 2 Zonal ventilation indices (IV $)$ before (clear columns) and after (hatched) histamine challenge. $U Z$ - upper zone; $M Z$-mid zone; LZ-lower zone.

were seen before histamine inhalation and in some subjects there were marked differences between the left and right lung (table 2). The regional distribution indices for ventilation are illustrated in fig 2 . In six subjects the distribution of ventilation resembled that found previously in normal subjects, ${ }^{4}$ with ventilation at the lung base exceeding that at the apex. There was, however, a much wider variation than normal, and in two subjects (Nos 3 and 4) the pattern of ventilation was reversed, with apical ventilation predominating in both lungs for subject 4 and in the left lung for subject 3 .

\section{After histamine challenge}

Regional alveolar ventilation per unit lung volume, (VA/VA) decreased in each lung after histamine challenge (table 2), which is consistent with an increase in airflow obstruction. The two lungs were not always affected to the same degree. In four subjects complete xenon equilibration had not occurred when the study was terminated after five minutes. In

Table 2 Alveolar ventilation per unit lung volume ( min $\left.^{-1}\right)$ for each lung before $\left(\lambda_{T}\right)$ and after $\left(\lambda_{\dot{T}}\right.$ histamine challenge

\begin{tabular}{|c|c|c|c|c|}
\hline \multirow{2}{*}{$\begin{array}{l}\text { Subject } \\
\text { No }\end{array}$} & \multicolumn{2}{|l|}{ Left lung } & \multicolumn{2}{|l|}{ Right lung } \\
\hline & $\begin{array}{l}\text { Before }\left(\lambda_{T}\right) \\
\text { histamine } \\
\text { challenge }\end{array}$ & $\begin{array}{l}\left.\text { After }(\lambda+)^{\circ}\right) \\
\text { histamine } \\
\text { challenge }\end{array}$ & $\begin{array}{l}\text { Before }\left(\lambda_{T}\right) \\
\text { histamine } \\
\text { challenge }\end{array}$ & $\begin{array}{l}\text { After }(\lambda+) \\
\text { histamine } \\
\text { challenge }\end{array}$ \\
\hline $\begin{array}{l}1 \\
2 \\
3 \\
4 \\
5 \\
6 \\
7 \\
8\end{array}$ & $\begin{array}{l}2.08 \\
1.73 \\
0.99 \\
1.31 \\
1.43 \\
2.97 \\
1.85 \\
1.66\end{array}$ & $\begin{array}{l}0.99 \\
0.47 \\
0.48 \\
0.23 \\
0.43 \\
1.89 \\
1.60 \\
0.43\end{array}$ & $\begin{array}{l}2.19 \\
2.08 \\
1.73 \\
1.16 \\
1.73 \\
2.77 \\
2.19 \\
1.81\end{array}$ & $\begin{array}{l}1.43 \\
0.69 \\
0.22 \\
0.20 \\
0.69 \\
1.60 \\
1.54 \\
0.34\end{array}$ \\
\hline
\end{tabular}

six subjects the distribution of regional ventilation changed after histamine from predominantly basal to predominantly apical (fig 2 ). In subjects 3 and 4 , who had a severe pre-existing abnormality of regional ventilation, the distribution of ventilation did not change (right lung only in the case of subject 3 ). In subject 3 the distribution of ventilation in the left lung changed from predominantly apical to predominantly basal. Induced bronchoconstriction was therefore greatest in those areas which were previously ventilated best and this presumably reflects the site of histamine deposition. The relative increase in regional lung volume after histamine was also greatest in the areas previously ventilated best.

\section{AEROSOL DEPOSITION}

Before histamine challenge

Several patterns of aerosol deposition were seen. Three subjects had normal scintiscan appearances for the size of aerosol with no central to peripheral gradient of deposition. Three subjects with airflow obstruction had increased central deposition, while the other two subjects showed increased peripheral deposition. These two subjects had previously shown the greatest derangements in regional ventilation. Two patterns of abnormal peripheral deposition were seen. In one instance increased deposition was patchy, with several "hot spots" (fig 3); in the other a large area of diffusely increased deposition was seen peripherally.

\section{After histamine challenge}

All subjects showed a significant shift in the pattern of aerosol deposition after bronchial provocation, with increased central deposition and less peripheral penetration (fig 4). In some subjects central deposition was so pronounced that individual main bronchi could be visualised.

Visual inspection suggested that the degree of central deposition after histamine challenge was proportional to the percentage decrement in FEV, 


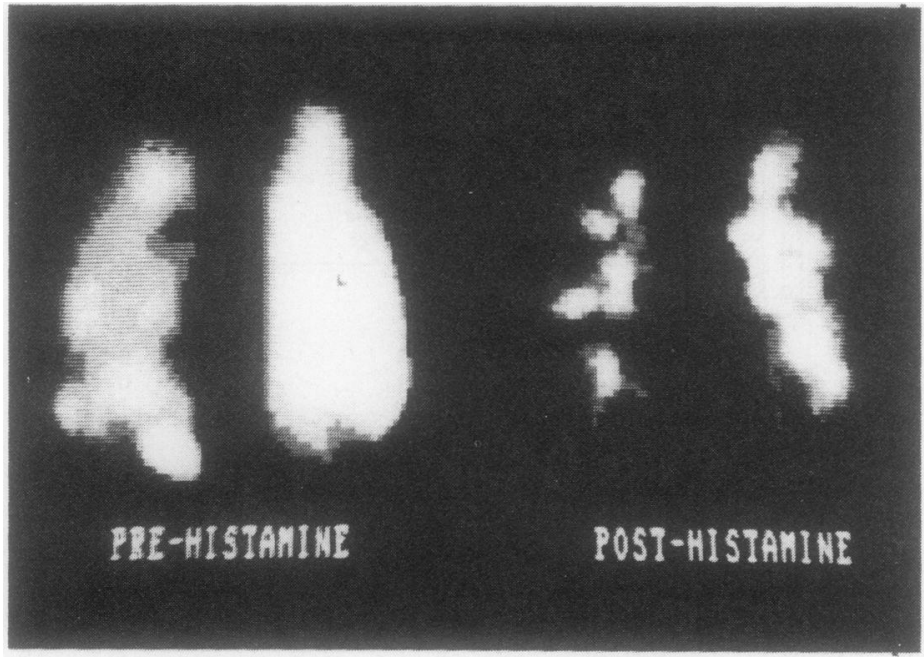

Fig 3 Subject 3: radioaerosol scintiscans showing focal areas of increased deposition in the left lung before histamine challenge (left) and intense central airway deposition after challenge (right).
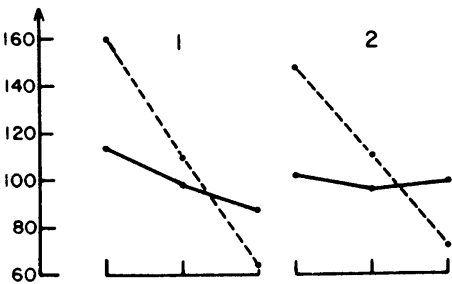

3
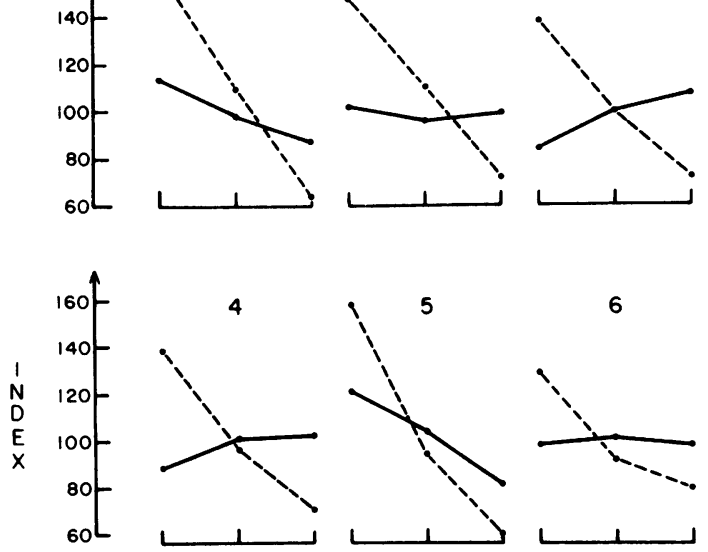

6

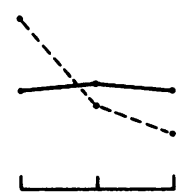

他

8

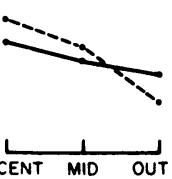

Fig 4 Combined regional deposition indices for both lungs for technetium $99 \mathrm{~m}$ sulphur colloid aerosol before and after histamine challenge in the eight subjects. The mean indices of five normal subjects are shown for comparison. The dotted line represents the posthistamine indices.

and this was confirmed by the positive correlation between change in histamine aerosol penetration and percentage fall in $\mathrm{FEV}_{1}(\mathrm{r}=0.83, \mathrm{p}<0.01)$ (fig 5).

The results from the radioaerosol studies were insufficiently sensitive to show any regional sequence in the vertical distribution of inhaled particles after bronchial challenge. This was primarily because heavy deposition in airways in the perihilar region created "hot spots" that overlapped all three arbitrary vertical zones.

\section{Discussion}

Our results for the mean indices of regional ventilation before bronchial challenge were similar to those previously observed in normal subjects. ${ }^{4}$ Individual regional ventilation indices showed a far greater variation than normal, but ventilation inhomogeneities are common in remissions of asthma. ${ }^{112}$ Before challenge two subjects showed a reversal of the normal pattern of ventilation, with impaired ventilation at the lung bases. This has been observed previously in asthmatic patients in remission. ${ }^{112}$ It is unlikely that airway reactivity to histamine differs between apex and base, and the regional response probably reflects the predominant site of histamine deposition. Previous work has shown a close relationship between aerosol deposition and regional ventilation, ${ }^{4}$ and provides an explanation of why the effects of histamine were greatest, at least initially, in the better ventilated regions. Support for this premise comes from the patient whose lung apex 


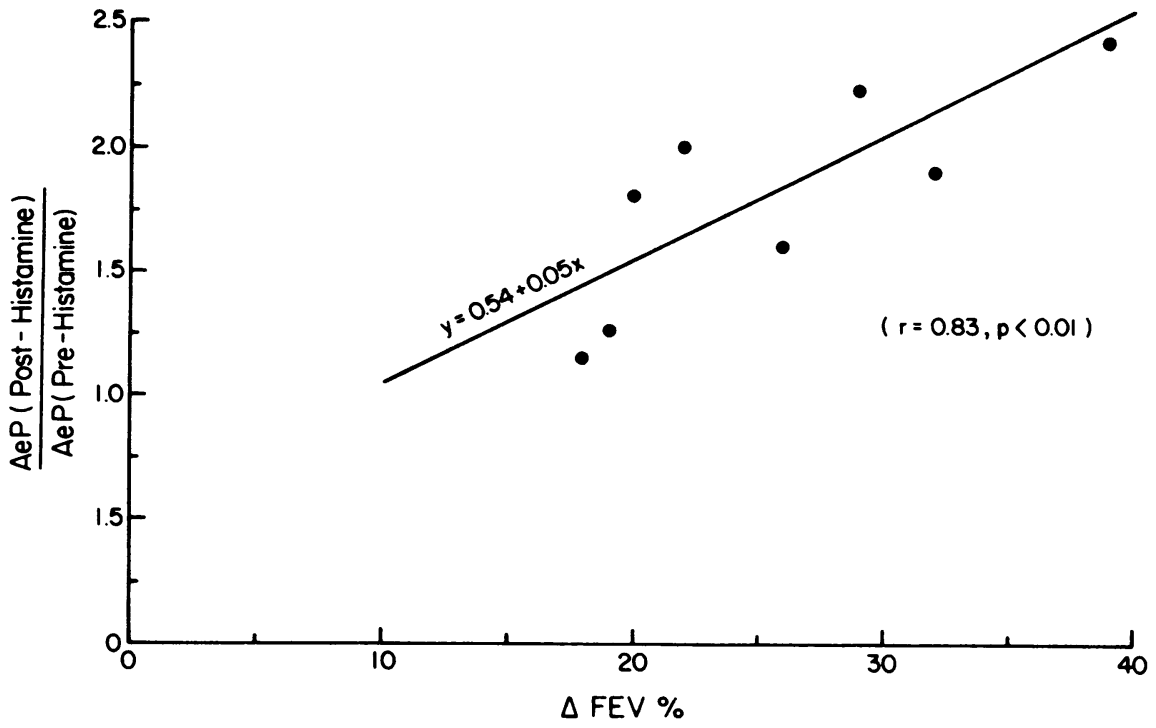

Fig 5 Correlation of the ratio of aerosol penetrance $(A e P)$ before and after histamine challenge with the percentage decrement in $F E V_{1}(r=0.83, p<0.01)$.

was ventilated best before challenge, but whose base became so after challenge.

Comroe and coworkers suggested that the arterial oxygen tension decreases after inhalation of bronchodilators because aerosol is carried almost entirely to the better ventilated regions of the lung, where it exerts its major effect. ${ }^{13}$ Watanabe and colleagues, examining the change in regional ventilation in patients with airways obstruction before and after an inhalation of a bronchodilator, ${ }^{14}$ showed that the response was highly variable; but in at least five patients regional ventilation showed the greatest improvement in the previously best ventilated zones. Dashe and colleagues, however, were unable to show regional changes in ventilation and perfusion when bronchodilators were administered by intermittent positive pressure breathing (IPPB). ${ }^{15}$ There are several possible explanations of why their results differed from our own and those of Watanabe and colleagues. ${ }^{14}$ Firstly, the technetium tracer and nebulised isoprenaline they used do not necessarily have the same intrapulmonary distribution. Secondly, particle transport is influenced not only by convective phenomena-that is, regional ventilation-but also by the propensity for particles to deposit in the proximal conducting airways as a result of impaction. This mechanism is important for particles around $3 \mu \mathrm{m}$, which is the usual size of particles generated by an IPPB ultrasonic nebuliser. The high flow rates and vortices generated by IPPB will increase proximal deposition from both inertial and turbulent impaction.

Because of the small size of the particles the histamine aerosol would be expected to be deposited preferentially in the lung periphery, although local disorders of airway geometry and increased turbulence may lead to increased deposition in conducting airways. ${ }^{16}$ Induced bronchoconstriction would also be expected to increase dead space deposition. Both vagal reflexes and a direct action on smooth muscle have been suggested as mechanisms by which histamine induces bronchoconstriction. ${ }^{17}$ Ruffin et al concluded that an inhaled histamine aerosol of $3 \mu \mathrm{m}$ exerts its main action on central airways, ${ }^{18}$ though they neglected to take into account the effect of an inhalation to total lung capacity on small airways obstruction, or the increased cross-sectional area of peripheral airways. Brown and associates found a predominantly large airway response to inhaled histamine in smokers and a predominantly small airway response in non-smokers, and attributed the differences to differing deposition sites. ${ }^{19}$

The acute response that follows inhalation challenge with histamine starts at around 30 seconds and peaks at about three minutes. ${ }^{1720}$ The recovery phase may last from 60 to 20 minutes, ${ }^{17}$ but since our method depends on an analysis of the initial portion of the washin curve any errors due to the wearing off of histamine should have been minor. Furthermore, the small airways show a more pro- 
longed response than the large airways, so small airway obstruction is likely to persist when the FEV has started to improve. ${ }^{21}$

As in the present study, Heckscher et al found that function deteriorated first and most often at the lung base and then later at the apex, with a tendency for the mid zones to be spared. ${ }^{12}$ The most likely explanation for this regional sequence is that inhaled bronchoconstrictor is preferentially deposited at the bases, where regional ventilation is greatest. This would lead to basal bronchoconstriction and antigen deposition elsewhere throughout the bronchial tree and hence to widespread airways constriction. Unfortunately our radioaerosol studies were insufficiently sensitive to show any regional sequence in the vertical distribution of the radioaerosol after challenge.

The exact mechanism for the different aerosol deposition pattern in disease is not known but several theories have been proposed. In subjects with chronic airways obstruction lobar, segmental, and subsegmental bronchi may undergo dynamic compression significantly earlier in expiration than they do in normal subjects. ${ }^{22}$ Abnormal collapse of large airways would predispose to aerosol deposition during expiration, and could explain the localised "hot spots" seen in this and previous studies. ${ }^{23-25}$ In asthma dynamic compression is unlikely to be the whole explanation since the increased tone in central airways makes them less compressible, ${ }^{26}$ and increases airflow resistance and the Reynolds number for a given flow. In these circumstances equal pressure points situated in central airways would move upstream to more peripheral airways, which are more compressible and therefore more likely to collapse. Consequently, for an equivalent degree of airways obstruction aerosol deposition in asthmatics should occur more peripherally than it does in subjects with emphysema.

Diffuse peripheral increased in deposition cannot be explained by dynamic compression of the small airways or turbulence. Moreover, small airway obstruction is fixed and uninfluenced by lung volumes. ${ }^{27}$ The formation of vortices in the obstructed peripheral airways will encourage mechanical mixing of inhaled and lung air, and increase the transfer of particles to resident air. This would predispose to aerosol deposition sedimentation and Brownian motion, and may explain the diffusely increased deposition noted in one subject. The lack of xenon retention in the affected areas argues against impaired regional ventilation (trapping) as the explanation for increased deposition.

Histamine leads to progressive airway narrowing and even greater aerodynamic filtration of aerosol. Aerosol penetrance is thus reduced in proportion to the increase in airflow limitation. The reduction in peripheral deposition after histamine challenge does not necesarily indicate less peripheral airways obstruction, and indeed.our results suggest that both large and small airways are affected. Ramanna et $a l,{ }^{28}$ Dore $e t a l,{ }^{24}$ and Dolovich $e t a l^{29}$ have all suggested that aerosol penetrance might be a more sensitive indicator of airways obstruction than spirometry. In our study aerosol imaging appeared to be as sensitive as the $\mathrm{FEV}_{1}$ measurements in determining the functional response and site of induced airways constriction. The deposition of bronchoactive substances in the better ventilated areas of the lung has certain implications. The delivery of bronchoconstrictors to better ventilated regions could produce more ventilation perfusion mismatching than a nore uniform distribution. Similarly, the penetration of therapeutic aerosols will be impeded by airways narrowing in the regions where they are most needed.

We thank Mrs A Gallie and Dr Martin King for their assistance. This work was supported by grants from the Ontario Ministry of Labour and the Ontario Thoracic Society.

\section{References}

${ }^{1}$ Pepys J, Hutchcroft BJ. Bronchial provocation tests in etiologic diagnosis and analysis of asthma. Am Rev Respir Dis 1975;112:829-59.

${ }^{2}$ Cockcroft DW, Killian DW, Mellin JJA, Hargreave FE. Bronchial reactivity to inhaled histamine: a method and clinical survey. Clin Allergy 1977;7:235-43.

${ }^{3}$ Morris JF, Koski A, Johnson LC. Spirometric standards for healthy non-smoking adults. Am Rev Respir Dis 1971;103:57-66.

4 Chamberlain -MJ, Morgan WKC, Vinitski S. Factors influencing the regional deposition of inhaled particles in man. Clin Sci 1983;64:69-78.

5 Atkins HA, Robertson JS, Croft BY, et al. Estimates of radiation absorbed dose from radioxenon in lung imaging. J Nucl Med Allied Sci 1970;21:459-65.

6 Susskind HL, Cohn SH, Ellis KJ, Richard P. Whole body retention of radioxenon. J Nucl Med Allied Sci 1980;18:462-71.

7 Van der Mark TW, Peset R, Beekhuis A, et al. An improved method for the analysis of xenon-133 washin and washout curves. J Nucl Med Allied Sci 1980;21:1029-34.

${ }^{8}$ Prato FS. The development of pulmonary radiation fibrosis in man. University of Toronto: PhD thesis, 1976.

${ }^{9}$ Hayes M, Taplin GV. Lung imaging with radioaerosols for the assessment of airway disease. Semin $\mathrm{Nucl}$ Med 1980;10:243-51.

${ }^{10}$ Bates DV, Christie RV. Intrapulmonary mixing of helium in health and emphysema. Clin Sci 1950;9:17-22.

11 Bentivoglio LG, Beerel F, Bryan AC, Stewart PB, Rose B, Bates DV. Regional pulmonary function studies 
with xenon-133 in patients with bronchial asthma. $J$ Clin Invest 1963;42:1193-200.

12 Heckscher T, Bass H, Oriol A, Rose B, Anthonisen BR, Bates DV. Regional lung function in patients with bronchial asthma. J Clin Invest 1968;47:1063-70.

${ }^{13}$ Comroe JH, Forster RE, Dubois AB, Briscoe WA, Carlson E. The lung. 2nd ed. Chicago: Year Book Publishers Inc, 1962:292.

${ }^{14}$ Watanabe S, Renzetti AD, Bigler A. Bronchodilator and corticosteroid effects on regional and total airway resistance in patients with asthma, chronic bronchitis and chronic pulmonary emphysema. Am Rev Respir Dis 1972;106:392-403.

is Dashe CK, Ponto RA, Ganapes CM, Drage CW, Kronenberg RS. The distribution of nebulised isoproterenol and its effect on regional ventilation and perfusion. Am Rev Respir Dis 1974;110:293-300.

${ }^{16}$ Lippman M, Yeates DB, Albert RE. Deposition, retention and clearance of inhaled particles. $\mathrm{Br} J$ Ind Med 1980;37:337-62.

${ }^{17}$ Laitinen LA. Histamine and metacholine challenge in the testing of bronchial reactivity. Scand J Respir Dis 1974;suppl 86:1-48.

${ }^{18}$ Ruffin RE, Dolovich MB, Wolff RK, Newhouse MT. The effects of preferential deposition of histamine in the human airway. Am Rev Respir Dis 1978;117:485-92.

19 Brown NE, McFadden ER, Ingram RH. Airway response to inhaled histamine in asymptomatic smokers and nonsmokers. J Appl Physiol 1977;42:508-13.

${ }^{20}$ Itkin IH. Bronchial hypersensitivity to mecholyl and his- tamine in asthma subjects. J Allergy 1967;40:245-56.

${ }^{21}$ Cade JF, Woolcock J, Rebuck AAS, Pain MCF. Lung mechanics during provocation of asthma. Clin Sci 1971;40:381-91.

22 Takishima T, Grimby G, Graham W, et al. Flow volume curves during quiet breathing, maximum voluntary ventilation and forced vital capacities in patients with obstructive lung disease. Scand $J$ Respir Dis 1967;48:384-93.

${ }^{23}$ Isawa T, Wasserman K, Taplin GV. Lung scintigraphy and pulmonary function studies in obstructive airway disease. Am Rev Respir Dis 1970;102:161-72.

${ }^{24}$ Dore EK, Poe ND, Ellestad MH, Taplin GV. Lung perfusion and inhalation scanning in pulmonary emphysema. Am J Roentgenol 1968;104:770-6.

${ }^{25}$ Lin MS, Goodwin DA. Pulmonary distribution of an inhaled radioaerosol in obstructive pulmonary disease. Radiology 1976;118:645-51.

${ }^{26}$ Olsen CR, Stevens AE, Mcllroy MB. Rigidity of trachea and bronchi during muscular constriction. $J$ Appl Physiol 1967;23:27-34.

${ }^{27}$ Macklem PT, Fraser RG, Brown WG. Bronchial pressure measurements in emphysema and bronchitis. $J$ Clin Invest 1965;44:897-905.

${ }^{28}$ Ramanna L, Tashkin DP, Taplin GV, et al. Radioaerosol lung imaging in chronic obstructive pulmonary disease. Chest 1975;68:634-40.

${ }^{29}$ Dolovich MB, Sanctis J, Rossman C, Newhouse MT. Aerosol penetrance: a sensitive index of peripheral airways obstruction. J Appl Physiol 1976;40:468-71. 